\title{
A Novel Pathway Underlying the Inhibitory Effects of Melatonin on Isolated Rat Urinary Bladder Contraction
}

\author{
June Hyun Han ${ }^{1}$, In Ho Chang ${ }^{2}$, Soon Chul Myung ${ }^{2}$, Moo Yeol Lee ${ }^{3}$, Won Yong Kim ${ }^{4}$, Seo Yeon Lee ${ }^{5}$, \\ Shin Young Lee ${ }^{6}$, Seung Wook Lee ${ }^{7}$, and Kyung Do Kim ${ }^{2}$ \\ ${ }^{1}$ Department of Urology, KEPCO Medical Foundation, Han-il General Hospital, Seoul 132-703, ${ }^{2}$ Department of Urology, Chung-Ang \\ University Hospital, Departments of ${ }^{3}$ Physiology, ${ }^{4}$ Microbiology, College of Medicine, Chung-Ang University, Seoul 156-755, ${ }^{5}$ Department \\ of Urology, Kwandong University Myungii Hospital, Goyang 412-270, ${ }^{6}$ Department of Urology, Seoul Medical Center, Seoul 131-130, \\ ${ }^{7}$ Department of Urology, Hanyang University Guri Hospital, Guri 471-701, Korea
}

\begin{abstract}
The aim of the present study was to elucidate the direct effects of melatonin on bladder activity and to determine the mechanisms responsible for the detrusor activity of melatonin in the isolated rat bladder. We evaluated the effects of melatonin on the contractions induced by phenylephrine (PE), acetylcholine ( $\mathrm{ACh})$, bethanechol $(\mathrm{BCh}), \mathrm{KCl}$, and electrical field stimulation (EFS) in 20 detrusor smooth muscle samples from Sprague-Dawley rats. To determine the mechanisms underlying the inhibitory responses to melatonin, melatonin-pretreated muscle strips were exposed to a calcium channel antagonist (verapamil), three potassium channel blockers [tetraethyl ammonium (TEA), 4-aminopyridine (4-AP), and glibenclamide], a direct voltage-dependent calcium channel opener (Bay K 8644), and a specific calcium/calmodulin-dependent kinase II (CaMKII) inhibitor (KN-93). Melatonin pretreatment $\left(10^{-8} \sim 10^{-6} \mathrm{M}\right)$ decreased the contractile responses induced by $\mathrm{PE}\left(10^{-9} \sim 10^{-4} \mathrm{M}\right)$ and Ach $\left(10^{-9} \sim 10^{-4} \mathrm{M}\right)$ in a dose-dependent manner. Melatonin $\left(10^{-7} \mathrm{M}\right)$ also blocked contraction induced by high $\mathrm{KCl}\left([\mathrm{KCl}]_{\mathrm{ECF}} ; 35 \mathrm{mM}, 70 \mathrm{mM}, 105 \mathrm{mM}\right.$, and $\left.140 \mathrm{mM}\right)$ and EFS. Melatonin $\left(10^{-7} \mathrm{M}\right)$ potentiated the relaxation response of the strips by verapamil, but other potassium channel blockers did not change melatonin activity. Melatonin pretreatment significantly decreased contractile responses induced by Bay K $8644\left(10^{-11} \sim 10^{-7} \mathrm{M}\right)$. KN-93 enhanced melatonin-induced relaxation. The present results suggest that melatonin can inhibit bladder smooth muscle contraction through a voltage-dependent, calcium-antagonistic mechanism and through the inhibition of the calmodulin/CaMKII system.
\end{abstract}

Key Words: Melatonin, Urinary bladder, Smooth muscles, Overactive bladder, Nocturia

\section{INTRODUCTION}

Nocturia is the complaint of having to wake at night to void [1], particularly in older adults [2]. Nocturia is often less responsive than other lower urinary tract symptoms after medical or surgical treatment for benign prostatic hyperplasia (BPH) [3]. Nocturia is a complex medical condition that can result from several factors, including reduced bladder capacity, the excessive production of urine at night (nocturnal polyuria), or a combination of these two causes. It can also result from a primary sleep disorder [4].

Melatonin (N-acetyl-5-methoxytryptamine) is a pineal

Received November 1, 2011, Revised December 22, 2011,

Accepted January 8, 2012

Corresponding to: Kyung Do Kim, Department of Urology, Chung-Ang University Hospital, 224-1, Heuksuk-dong, Dongjak-gu, Seoul 156-755, Korea. (Tel) 82-2-6299-1785, (Fax) 82-2-6294-1406, (E-mail) kim14141@hananet.net

(1) (8) This is an Open Access article distributed under the terms of the Creative Commons Attribution Non-Commercial License (http:/ Creative Commons Attribution Non-Commercial License (http:/ creativecommons.org/licenses/by-nc/3.0) which permits unrestricted non-commercial gland hormone secreted predominantly at night. Nocturnal production of melatonin is impaired in older adults, and several clinical trials have demonstrated that exogenous administration of melatonin to this group improves sleep $[5,6]$ and habitual nocturnal voiding $[7,8]$. Melatonin increases bladder capacity and decreases urine volume via a central nervous system (CNS) effect [9] and also relaxes involuntary or increased bladder contractions via peripheral nervous system effects [10]. It is a prime physiological determinant of circadian rhythms and influences the physiological decrease in urine output and frequency at night in healthy individuals, either directly or indirectly through effects on other hormones [1]. Melatonin exerts many of its physiological actions through interaction with the membrane receptors MT1 and MT2 and intracellular proteins such as quinine reductase 2, calmodulin, calreticulin, and tubulin. Melatonin receptors are expressed in various parts of the CNS and in peripheral organs including kidney, bladder, and prostate [11].

Melatonin was originally described as a potent anti-

ABBREVIATIONS: PE, phenylephrine; Ach, acetylcholine; BCh, bethanechol; EFS, electrical field stimulation; TEA, tetraethyl ammonium; 4-AP, 4-aminopyridine; CaMKII, calcium/calmodulindependent kinase II; OAB, overactive bladder. 
oxidant [12]. Melatonin has a modulatory effect on gastrointestinal smooth muscle motility, and both contractile and relaxant effects have been reported $[10,13]$. In the bladder, melatonin inhibits ACh- and KCl-induced contraction [10]. However, the exact mechanism responsible for the effects of melatonin on smooth muscle is unknown.

Therefore, we performed the present study to elucidate the direct effect of melatonin on bladder activity and to determine the mechanism underlying melatonin-based modulation of detrusor activity in isolated rat bladder tissue.

\section{METHODS}

\section{Preparation of rat bladder strips and measurement of tension}

A total of 20 Sprague-Dawley rats, weighing 150 200 $\mathrm{g}$, were used in this study. All protocols were performed in accordance with the recommendations of the ethics Committee for the Protection of Persons and Animals at the Institute of Medical Science, Chung-Ang University, Seoul, Korea. The rats were asphyxiated by placement into a tight container with $100 \% \mathrm{CO}_{2}$ gas for 30 sec and were then sacrificed by a cut to the carotid artery. The abdomen was opened and the urinary bladder was surgically removed and transferred to a Petri dish containing HEPES buffered physiological salt solution (composition in $\mathrm{mM}$ : $\mathrm{NaCl}, 140 ; \mathrm{KCl}, 4 ; \mathrm{CaCl}_{2}, 2 ; \mathrm{MgCl}_{2}, 1 ; \mathrm{NaHPO}_{4}, 1.2$; L-glucose, 11; HEPES, 5; pH adjusted to 7.4 with $\mathrm{NaOH}$ ) with $100 \% \mathrm{O}_{2}$ saturation. The strips were then trimmed to $2 \times 1 \times 5$ $\mathrm{mm}$ and the urothelium was removed. The strips were prepared from the lower half of the bladder.

The strips were mounted in a $20 \mathrm{ml}$ organ bath filled with physiological salt solution (composition in $\mathrm{mM}: \mathrm{NaCl}$, 114; $\mathrm{NaHCO}_{3}, 26 ; \mathrm{KCl}, 4 ; \mathrm{CaCl}_{2}, 2 ; \mathrm{MgCl}_{2}, 1 ; \mathrm{NaHPO}_{4}, 1.2$; L-glucose, 11; HEPES, 5; $\mathrm{pH}$ adjusted to 7.4 with $\mathrm{HCl}$ ). The solution in the bath was bubbled with mixed gas $\left(95 \% \mathrm{O}_{2}\right.$, $5 \% \mathrm{CO}_{2}$ ) and maintained at $37^{\circ} \mathrm{C}$ and exchanged at $30 \mathrm{~min}$ intervals. The strips were connected to an isometric force transducer (52-9545, Harvard Instruments, London, UK) and the measurements were recorded on a MacLab 4e digital recording system (AD Instruments, Bella Vista, NSW, Australia). Resting tension was adjusted to $0.2 \mathrm{~g}$ over 60 min for the equilibration period.

\section{Contractile responses of the strips}

1. Contraction induced by acetylcholine (ACh), bethanechol (BCh), phenylephrine (PE), or $\mathrm{KCl}$

Strips were pretreated with melatonin $\left(10^{-8} \sim 10^{-6} \mathrm{M}\right)$ for $10 \mathrm{~min}$, followed by successive logarithmic increments of $\mathrm{PE}, \mathrm{ACh}$, or BCh (all $10^{-9} \sim 10^{-4}$ ).

\section{Contraction induced by $\mathrm{KCl}$ or electrical field stimulation (EFS)}

For $\mathrm{KCl}$ experiments, strips were pretreated with $10^{-7}$ $\mathrm{M}$ melatonin followed by $\mathrm{KCl}$. $\mathrm{KCl}$ concentrations in the extracellular fluid ([KCl $]_{\mathrm{ECF}}$ ) for the four $\mathrm{KCl}$-treated conditions were $35 \mathrm{mM}, 70 \mathrm{mM}, 105 \mathrm{mM}$, and $140 \mathrm{mM}$. EFS was performed using two platinum plate electrodes $(5 \times 10$ $\mathrm{mm})$ set parallel to each other beside the strips. Electrical impulses were delivered with a stimulator (6012, Harvard Instruments, London, UK). The strips were stimulated with rectangular pulses of $0.2 \mathrm{msec}$ and $50 \mathrm{~V}$, at a stimulation frequency of $1 \sim 40 \mathrm{~Hz}$. Trains of pulses lasted for $3 \mathrm{sec}$, and there was an interval of 2 min between stimulations.

\section{Mechanisms responsible for the relaxation responses to melatonin}

The basal tension of each strip was adjusted to the optimal isometric tension, at which contraction elicited by $\mathrm{PE}$ $10^{-5} \mathrm{M}$ was maximal. After pretreatment with $10^{-7} \mathrm{M}$ melatonin, relaxation was measured in response to successive logarithmic increments of a calcium channel blocker (verapamil; $10^{-9} \sim 10^{-4} \mathrm{M}$ ). Melatonin-induced inhibition of dose-dependent PE $\left(10^{-9} \sim 10^{-4}\right)$-induced contraction responses was measured in the presence of three potassium channel blockers [tetraethyl ammonium (TEA; $1 \mathrm{mM}$ and $10 \mathrm{mM}$ ), 4-aminopyridine (4-AP; $10^{-5} \mathrm{M}$ ), and $10^{-5} \mathrm{M}$ glibenclamide]. After pretreatment with $10^{-7} \mathrm{M}$ melatonin, Bay K 8644 (a calcium channel opener; $10^{-11} \sim 10^{-7} \mathrm{M}$ )-induced contractions were assessed. After bladder strips were incubated for $10 \mathrm{~min}$ in the absence or the presence of melatonin $\left(10^{-7} \mathrm{M}\right)$ alone or in combination with KN-93 [a specific calcium/calmodulin-dependent kinase II (CaMKII) inhibitor: $10^{-6} \mathrm{M}$ ], differences in $\mathrm{KCl}(35 \mathrm{mM})$-induced contraction were evaluated.

\section{Solutions and reagents}

All chemicals were obtained from Sigma Chemical Company (St. Louis, MO, USA).

\section{Statistical analysis}

The SPSS software package version 14.0 (Statistical Package for Social Sciences ${ }^{\mathrm{TM}}$, Chicago, IL, USA) was used for the statistical analysis. Data are representative of more than five replicates. Statistical analysis was performed by Student's $t$-test and ANOVA, with significance at $\mathrm{p}<0.05$.

\section{RESULTS}

\section{Melatonin pretreatment blocks contraction induced by} $P E, A C h$ and $B C h$ in a dose-dependent manner

Melatonin alone $\left(10^{-8} \sim 10^{-6} \mathrm{M}\right)$ did not change strip relaxation (data not shown). However, pretreatment with $10^{-8}$ $\sim 10^{-6} \mathrm{M}$ melatonin decreased the contractile responses induced by $\mathrm{PE}\left(10^{9} \sim 10^{-4} \mathrm{M}\right)$ in a dose-dependent manner $(\mathrm{n}=8$, Fig. 1A). Melatonin also attenuated ACh- and BCh-induced $\left(10^{-9} \sim 10^{-4} \mathrm{M}\right)$ contractions, which were stronger than PE contractions; however, the inhibitory effects of melatonin on contractions were not reversed by luzindole (a melatonin-receptor antagonist) $(n=12$, Fig. $1 B ; n=12$, Fig. 2A).

\section{Melatonin inhibits contractions induced by $\mathrm{KCl}$ and EFS}

Melatonin pretreatment $\left(10^{-7} \mathrm{M}\right)$ decreased induced contractions at four $\mathrm{KCl}$ concentrations $\left([\mathrm{KCl}]_{\mathrm{ECF}} ; 35 \mathrm{mM}, 70\right.$ $\mathrm{mM}, 105 \mathrm{mM}$, and $140 \mathrm{mM})\left(\mathrm{n}=8\right.$, Fig. 2B). Melatonin $\left(10^{-7}\right.$ M) also inhibited contractions induced by EFS $(1 \sim 40 \mathrm{~Hz})$ $(\mathrm{n}=8$, Fig. 3A). 

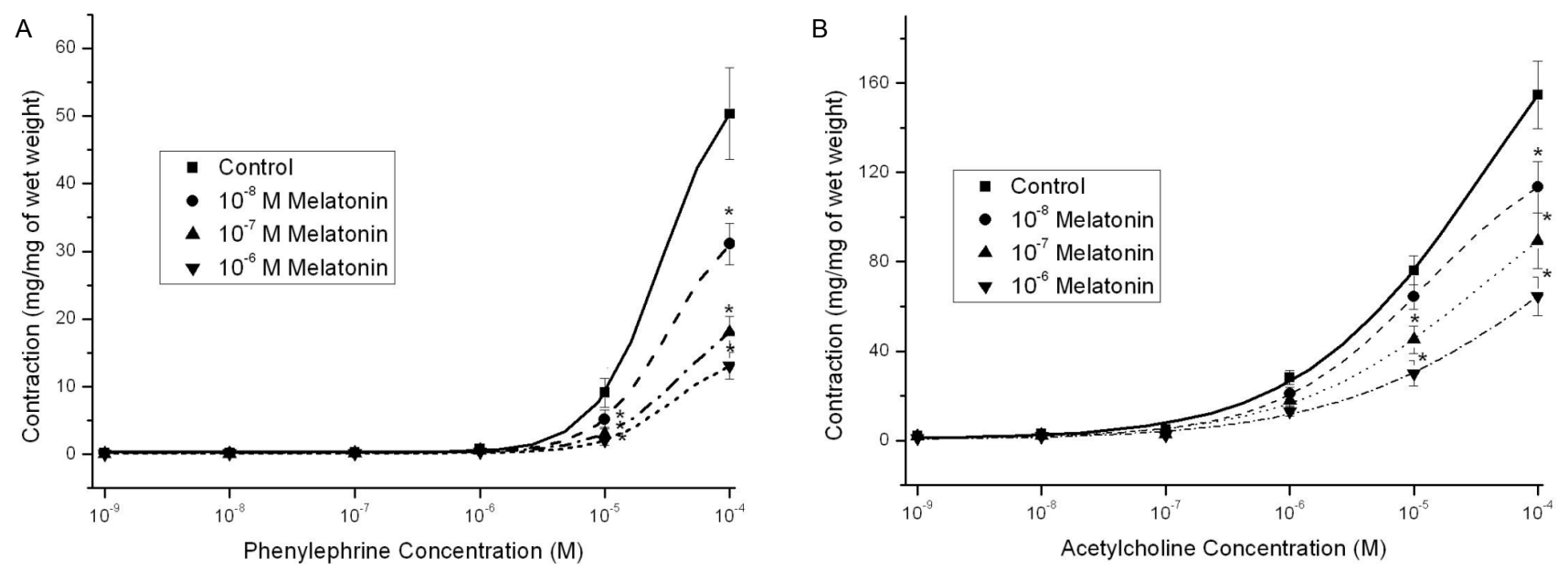

Fig. 1. Effects of melatonin pretreatment $\left(10^{-8} \sim 10^{-6} \mathrm{M}\right)$ on the concentration-response curve for phenylephrine $\left(10^{9} \sim 10^{-4} \mathrm{M}\right)$ and acetylcholine $\left(10^{-9} \sim 10^{-4} \mathrm{M}\right)$ in Sprague-Dawley rat detrusor smooth muscles. (A) Pretreatment with melatonin dose-dependently decreased the contractile responses induced by phenylnephrine ( $\mathrm{n}=8$ in each). (B) Melatonin blocked acetylcholine-induced contractions, which were stronger than phenylnephrine contractions $(\mathrm{n}=12$ in each). Asterisk means $\mathrm{p}<0.05$. Each point represents the mean \pm standard error of means (SEM); if the SEMs were not shown, the bars fall within the size of the symbols.
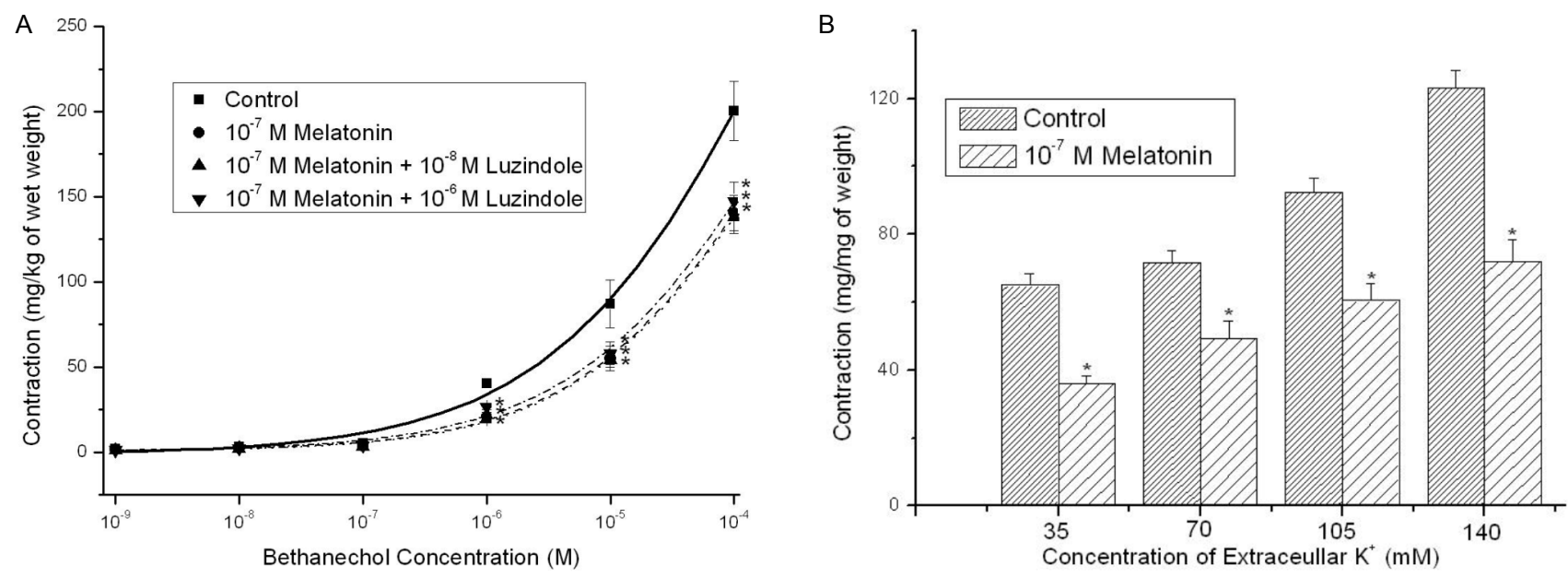

Fig. 2. Effects of melatonin pretreatment $\left(10^{-8} \sim 10^{-6} \mathrm{M}\right)$ on the concentration-response curve for bethanechol $\left(10^{-9} \sim 10^{-4} \mathrm{M}\right)$ and effects of $10^{-7} \mathrm{M}$ melatonin pretreatment on the KCl-induced contractions $\left([\mathrm{KCl}]_{\mathrm{ECF}} ; 35 \mathrm{mM}, 70 \mathrm{mM}, 105 \mathrm{mM}\right.$ and $\left.140 \mathrm{mM}\right)$ in Sprague-Dawley rat detrusor smooth muscles. (A) Melatonin blocked bethanechol-induced contractions, which were stronger than phenylnephrine contractions, but contraction inhibition effects of the melatonin were not reversed by luzindazole (a melatonin receptor antagonist) ( $\mathrm{n}=12 \mathrm{in}$ each). (B) The melatonin inhibited the contractions at all four conditions of high extracellular $\mathrm{KCl}$ concentrations ( $\mathrm{n}=8 \mathrm{in}$ each). Asterisk means $\mathrm{p}<0.05$. Each point represents the mean \pm standard error of means (SEM).

\section{Mechanisms of melatonin inhibition through calcium channel blocking effects}

Melatonin $\left(10^{-7} \mathrm{M}\right)$ potentiated the relaxation induced by treatment with the calcium channel antagonist (verapamil; $10^{-9} \sim 10^{-4}$ M) (n=8, Fig. 3B). However, none of the potassium channel blockers [TEA $(1 \mathrm{mM}$ and $10 \mathrm{mM}), 4-\mathrm{AP}$ $\left(10^{-5} \mathrm{M}\right)$, and glibenclamide $\left(10^{-5} \mathrm{M}\right)$ ] changed melatonin activity (data not shown). The contractile responses induced by the direct calcium channel opener (Bay K 8644; $10^{-11} \sim$ $\left.10^{-7} \mathrm{M}\right)$ were significantly decreased by $10^{-7} \mathrm{M}$ melatonin pretreatment (n=6, Fig. $4 \mathrm{~A})$. KN-93 at $10^{-6} \mathrm{M}$ concentration enhanced melatonin-induced inhibition of KCl-induced con- tractions (n=12, Fig. 4B).

\section{DISCUSSION}

Detrusor overactivity is frequently associated with overactive bladder (OAB) symptoms and is urodynamically characterized by involuntary detrusor contractions during bladder filling [1]. Large-scale, randomized and controlled studies have shown that patients receiving any type of oral antimuscarinic agent report a significant improvement in $\mathrm{OAB}$ symptoms [14]. However, despite these initial positive responses, antimuscarinics may fall short because of substantial side effects, insufficient effects on continuing incon- 

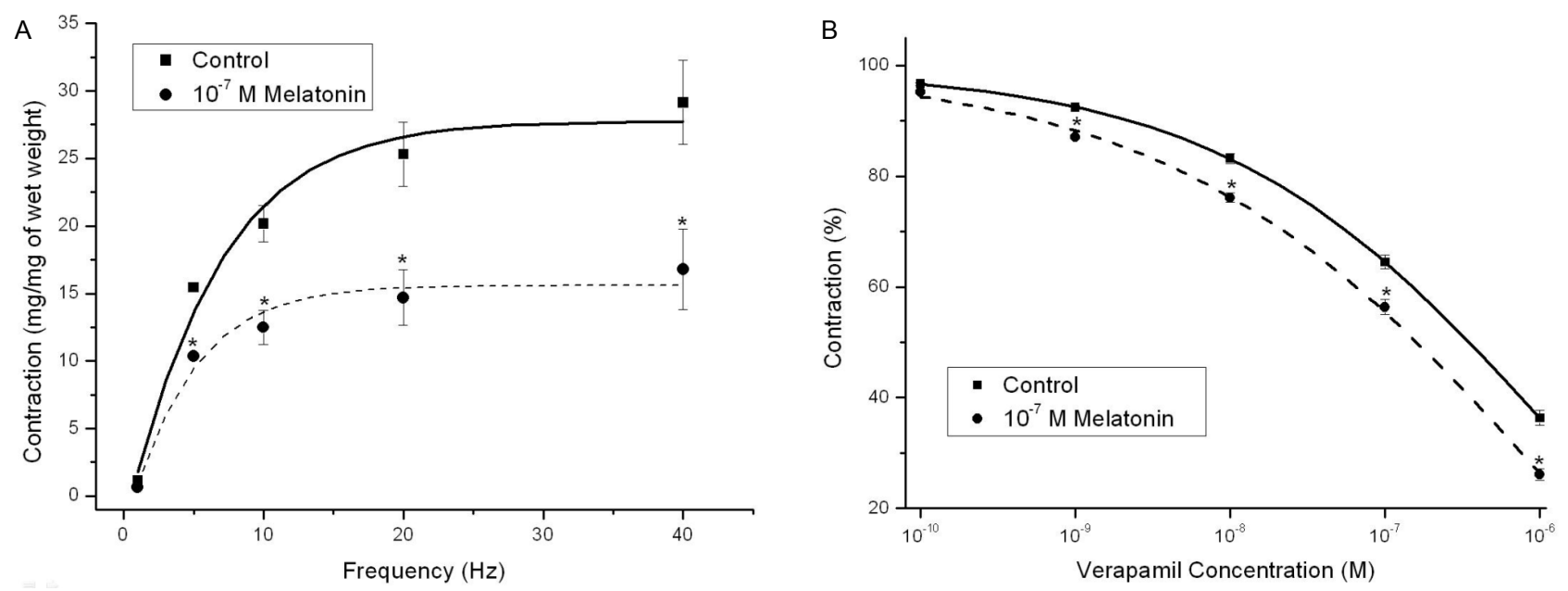

Fig. 3. Effects of $10^{-7} \mathrm{M}$ melatonin pretreatment on the frequency-response curve for electrical field stimulation (EFS, $1 \sim 40 \mathrm{~Hz}$ ) and effects of $10^{-7} \mathrm{M}$ melatonin pretreatment on the concentration-response curve for verapamil relaxation $\left(10^{-9} \sim 10^{-4} \mathrm{M}\right)$ in Sprague-Dawley rat detrussor muscles. (A) The melatonin significantly inhibited the EFS-induced contractions ( $\mathrm{n}=8$ in each). (B) The basal tension of each strip was adjusted to the optimal isometric tension at which contraction with phenylephrine 10-5 $\mathrm{M}$ was maximal. The curve was slightly but significantly inhibited by melatonin pretreatment $(n=8$ in each). Asterisk means $p<0.05$. Each point represents the mean \pm standard error of means (SEM) of the results.
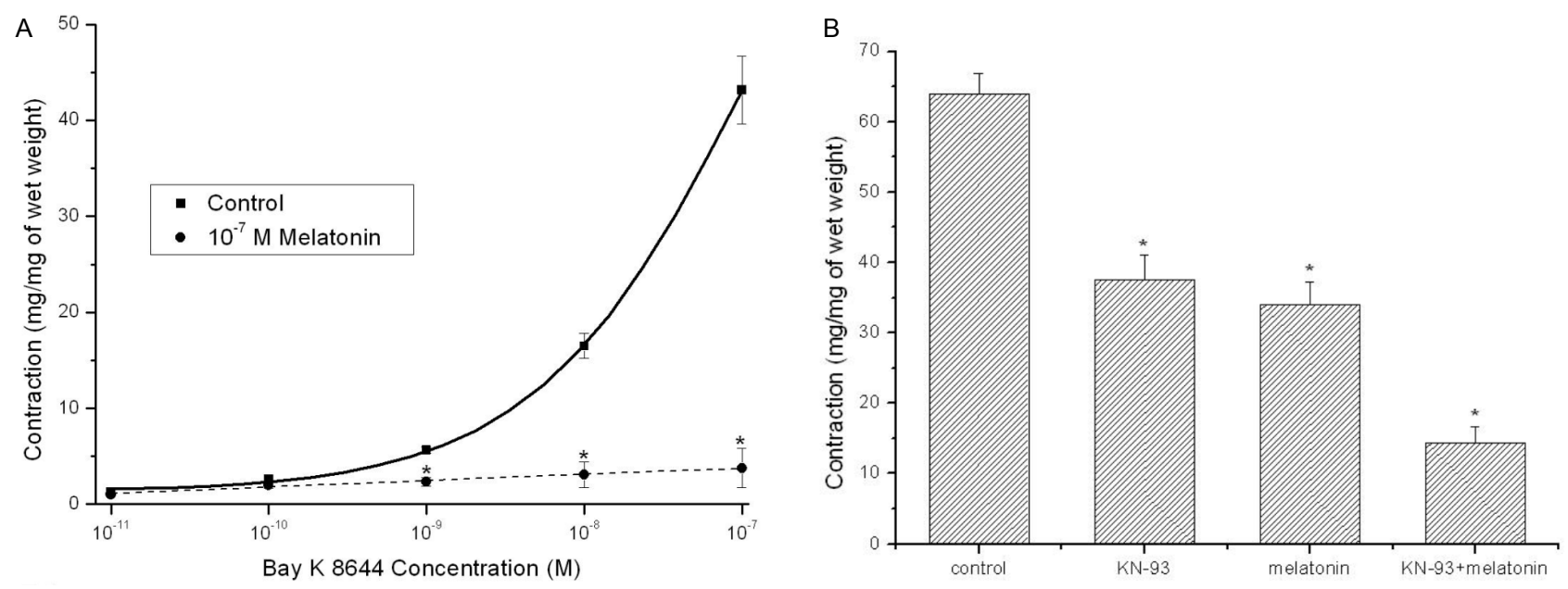

Fig. 4. Effects of $10^{-7} \mathrm{M}$ melatonin pretreatment on the concentration-response curve for Bay $\mathrm{K} 8644$ contraction $\left(10^{-11} \sim 10^{-7} \mathrm{M}\right)$ in Sprague-Dawley rat detrussor muscles and in the absence or the presence of melatonin $\left(10^{-7} \mathrm{M}\right.$ ) alone or combination with $\mathrm{KN}-93$ (a specific calcium/calmodulin-dependent kinase II inhibitor: $\left.10^{-6} \mathrm{M}\right)$, the differences of $\mathrm{KCl}(35 \mathrm{mM})$-induced contraction were evaluated. (A) The contractile responses of Bay K 8644 were almost completely inhibited by melatonin ( $\mathrm{n}=6$ in each). (B) KN-93 at $10^{-6} \mathrm{M}$ concentration enhanced the melatonin-induced inhibiting effects of the KCl-induced contraction ( $n=12$ in each). Asterisk means $p<0.05$. Each point represents the mean \pm standard error of means (SEM) of the results.

tinence, and long term compliance problems [15].

Melatonin is short-lived, with a half-life of only 40 to 50 minutes. Melatonin is safe in older adults, with few adverse effects. Documented side effects include decreased body temperature, sedation, headache, depression, tachycardia, and pruritus [16]. Melatonin, either alone or in combination with other agents, may help some patients in whom current options are ineffective or contraindicated. Onur et al. [17] reported that the combined use of low dose trospium and melatonin exerted strong in vitro inhibition of agonist-induced contractions in rat bladder strips.

Nocturnal production of melatonin is impaired in older adults. Drake et al. [7] showed that the administration of melatonin ( $2 \mathrm{mg} /$ day) for four weeks improved nocturia safely in patients with bladder outlet obstruction, and Sugaya et al. [8] reported that the night-time serum melatonin level was significantly lower in elderly persons than in younger persons. Furthermore, the night serum melatonin level in elderly persons with nocturia was lower than that in elderly persons without nocturia. Several clinical trials have demonstrated that exogenous administration of melatonin to this group can improve sleep disorders $[5,6]$. The use of a controlled-release melatonin formulation enables the maintenance of melatonin concentrations that are 
sufficiently effective to improve sleep in older adults throughout the night, with a single low dose [5]. Even in those patients with obvious medical reasons for nocturia, sleep disorders are the source of almost all awakenings from sleep and can contribute to habitual rising at night to urinate [18].

Melatonin, an endogenous hormone, inhibits bladder contractions induced by PE, ACh, and EFS in a dose-dependent manner. Semerciöz et al. [10] similarly reported that melatonin inhibits ACh-induced contractions in isolated bladder strips from guinea pigs. However, neither the effect of melatonin on adrenoceptor agonist-induced contraction nor the mechanism of action underlying this effect has been previously studied. Adrenoceptors play a prominent role in the pathogenesis of lower urinary tract symptoms and related irritative bladder symptoms [19]. In the present study, melatonin alone did not induce the relaxation response in the bladder strips, but melatonin did inhibit Ach-, BCh-, PE-, and EFS-induced contraction. Melatonin therefore has potential as a candidate bladder-calming modulator.

Melatonin exerts many of its physiological actions through interaction with the membrane receptors MT1 and MT2 and intracellular proteins such as quinine reductase 2, calmodulin, calreticulin, and tubulin. Melatonin receptors are expressed not only in the bladder but also in the prostate [11]. Melatonin has dual effects on the vasculature, with vasoconstriction through MT1 and vasodilation through MT2 [20]. However, in the present study, the contraction inhibitory effects of melatonin were not reversed by luzindole (a melatonin receptor antagonist). These results offer the possibility that melatonin-induced inhibition of bladder contraction may be mediated by the direct modulation of intracellular proteins because melatonin has the permeability of cell membrane.

Melatonin may also influence bladder contractility via calmodulin [21]. Melatonin can bind to $\mathrm{Ca}^{2+}$-activated calmodulin with high affinity and prevent it from activating myosin light-chain kinase, leading to decreased contractility [21]. Similarly, melatonin may directly affect the ion channels responsible for regulating bladder contraction or changing membrane potentials that affect other ion channels [12]. KN-93 selectively inhibits CaMKII activity by binding directly and selectively to the calmodulin binding site of CaMKII and preventing the association of calmodulin and CaMKII [22]. Our study found that KN-93 enhanced the melatonin-induced relaxation response in the bladder strips, indicating that melatonin may act on the calmodulin/CaMKII system.

Experiments involving myometrial contractions showed that melatonin can inhibit spontaneous and oxytocin-induced contractions in pregnant and non-pregnant rats [12]. Melatonin inhibits KCl-induced contractions in isolated bladder strips from guinea pigs [10]. In the present study, melatonin inhibited KCl-induced contraction. Melatonin potentiated the relaxation response of the bladder induced by verapamil, but potassium channel blockers did not change melatonin activity. In general, high $\mathrm{K}^{+}$-induced contraction is known to be evoked by $\mathrm{Ca}$ influx through the opening of voltage-dependent $\mathrm{Ca}$ channel. So the contraction is independent pathway from the $\mathrm{K}$ channel activity. Moreover, melatonin decreased the contractile responses induced by Bay K $8644\left(10^{-11} \sim 10^{-7} \mathrm{M}\right)$, indicating the potential antagonism of voltage-dependent $\mathrm{Ca}^{2+}$ channels. Melatonin may therefore act as a calcium antagonist on rat detrusor muscles.
In conclusion, the decrease in bladder contraction induced by melatonin may be mediated by the inhibition of the calmodulin/CaMKII system and voltage-dependent calcium channels in the rat bladder. Whether these two mechanisms act independently or in a complementary manner requires further study.

\section{ACKNOWLEDGEMENTS}

This study was supported by a grant from the Korea Healthcare Technology R\&D Project, Ministry for Health, Welfare, and Family Affairs, Republic of Korea (A085138).

\section{REFERENCES}

1. Abrams P, Cardozo L, Fall M, Griffiths D, Rosier P, Ulmsten U, Van Kerrebroeck P, Victor A, Wein A. Standardisation Sub-Committee of the International Continence Society. The standardisation of terminology in lower urinary tract function: report from the standardisation sub-committee of the International Continence Society. Urology. 2003;61:37-49.

2. Wein A, Lose GR, Fonda D. Nocturia in men, women and the elderly: a practical approach. BJU Int. 2002;90 Suppl 3:28-31.

3. Homma Y, Yamaguchi T, Kondo Y, Horie S, Takahashi S, Kitamura T. Significance of nocturia in the International Prostate Symptom Score for benign prostatic hyperplasia. $J$ Urol. 2002;167:172-176.

4. Appell RA, Sand PK. Nocturia: etiology, diagnosis, and treatment. Neurourol Urodyn. 2008;27:34-39.

5. Garfinkel D, Laudon M, Nof D, Zisapel N. Improvement of sleep quality in elderly people by controlled-release melatonin. Lancet. 1995;346:541-544.

6. Haimov I, Lavie P, Laudon M, Herer P, Vigder C, Zisapel N. Melatonin replacement therapy of elderly insomniacs. Sleep. 1995;18:598-603.

7. Drake MJ, Mills IW, Noble JG. Melatonin pharmacotherapy for nocturia in men with benign prostatic enlargement. $J$ Urol. 2004;171:1199-1202.

8. Sugaya K, Nishijima S, Miyazato M, Kadekawa K, Ogawa Y. Effects of melatonin and rilmazafone on nocturia in the elderly. $J$ Int Med Res. 2007;35:685-691.

9. Matsuta Y, Yusup A, Tanase K, Ishida H, Akino H, Yokoyama O. Melatonin increases bladder capacity via GABAergic system and decreases urine volume in rats. J Urol. 2010;184:386-391.

10. Semerciöz A, Onur R, Ayar A, Orhan I. The inhibitory role of melatonin on isolated guinea-pig urinary bladder: an endogenous hormone effect. BJU Int. 2004;94:1373-1376.

11. Pandi-Perumal SR, Trakht I, Srinivasan V, Spence DW, Maestroni GJ, Zisapel N, Cardinali DP. Physiological effects of melatonin: role of melatonin receptors and signal transduction pathways. Prog Neurobiol. 2008;85:335-353.

12. Ayar A, Kutlu S, Yilmaz B, Kelestimur H. Melatonin inhibits spontaneous and oxytocin-induced contractions of rat myometrium in vitro. Neuro Endocrinol Lett. 2001;22:199-207.

13. Thor PJ, Krolczyk G, Gil K, Zurowski D, Nowak L. Melatonin and serotonin effects on gastrointestinal motility. J Physiol Pharmacol. 2007;58 Suppl 6:97-103.

14. Abrams P, Andersson KE. Muscarinic receptor antagonists for overactive bladder. BJU Int. 2007;100:987-1006.

15. Drake MJ. Emerging drugs for treatment of overactive bladder and detrusor overactivity. Expert Opin Emerg Drugs. 2008;13: 431-446.

16. Nowak JZ, Zawilska JB. Melatonin and its physiological and therapeutic properties. Pharm World Sci. 1998;20:18-27.

17. Onur R, Ozcan M, Tuygun U, Ozan T, Ayar A, Orhan I. Effects of combined use of trospium chloride and melatonin on in vitro contractility of rat urinary bladder. Urology. 2010;75:873-877.

18. Pressman MR, Figueroa WG, Kendrick-Mohamed J, Greenspon 
LW, Peterson DD. Nocturia. A rarely recognized symptom of sleep apnea and other occult sleep disorders. Arch Intern Med. 1996;156:545-550.

19. Salvatore S, Soligo M, Proietti F, Citterio S, Artibani W, Milani R. Overactive bladder syndrome: considerations in pharmacotherapy and new perspectives. Eur J Obstet Gynecol Reprod Biol. 2005;120:129-133.

20. Cogé F, Guenin SP, Fery I, Migaud M, Devavry S, Slugocki C, Legros C, Ouvry C, Cohen W, Renault N, Nosjean O, Malpaux B, Delagrange P, Boutin JA. The end of a myth: cloning and characterization of the ovine melatonin MT(2) receptor. Br J Pharmacol. 2009;158:1248-1262.

21. Ouyang H, Vogel HJ. Melatonin and serotonin interactions with calmodulin: NMR, spectroscopic and biochemical studies. Biochim Biophys Acta. 1998;1383:37-47.

22. Ozveren E, Korkmaz B, Buharalioglu CK, Tunctan B. Involvement of calcium/calmodulin-dependent protein kinase II to endotoxin-induced vascular hyporeactivity in rat superior mesenteric artery. Pharmacol Res. 2006;54:208-218. 